\title{
THE WESTERN THORACIC SURGICAL ASSOCIATION
}

\section{Announcement of 2000 Annual Meeting}

Successful essayists must deliver the complete manuscript at the time of presentation. The manuscript must be in a form acceptable to The Journal of Thoracic and Cardiovascular Surgery and must not exceed 3000 words without illustrations. The essay length must be reduced appropriately when figures or tables are included.

\section{Samson Resident Prize Essay}

The Association offers a prize for the best manuscript on a topic of interest to thoracic surgeons in honor of Paul C. Samson, MD. Candidates for the prize must be in a training program in the United States or Canada. The one essayist whose abstract, manuscript, and presentation are judged most outstanding will receive a $\$ 2000$ cash award following the presentation of all papers in Hawaii. The conditions for abstract submission, presentation, and publication as described above will apply. In addition, the Samson Resident Prize Essay box in the lower left hand corner of the form should be checked. A covering letter from the Chief of Service of the training program indicating the individual's year of training and the proportion of the work performed by the resident must be submitted. The authors of the abstracts chosen for the program will make up the finalists and were notified by February 11, 2000, that they must submit six completed manuscripts for review by the Prize Essay Committee. The Prize Essay committee will make its selection following the presentation of all papers.

\section{Application for membership}

Applications for membership in the Association must have been received by the Membership Committee Chairman no later than March 1, 2000, to be considered at the following annual meeting. Applicants must be sponsored by three members of the Association who are not members of the Membership Committee. Application forms will be issued only to sponsoring members.

Address correspondence to:

Chairman, Membership Committee

The Western Thoracic Surgical Association

Thirteen Elm Street

Manchester, Massachusetts 01944

(978) 526-8330; fax (978) 526-4018

Vaughn A. Starnes, MD, Secretary 